table-lands, in determining the continuance and the direction of the course of cyclones; and the influence of isolated mountains and mountainous ridges in breaking up a cyclone into two distinct cyclones, which, from the difficulty necessarily experienced by seamen in interpreting the complex phenomena attending them, often prove so destructive in their effects.

\section{SEISMOLOGY IN JAPAN}

THE first earthquake that I ever felt took place about 2 a.m. on the night of April Io, 1876. On this night, which was soon after my arrival in Yedo, I had been installed in a new house. To be absolutely alone in a large partially furnished dwelling in a strange land, and then in the dead of night to be wakened by a swinging motion of the bedstead, a rattling of windows, creaking of timbers, and flapping of pictures was more than bewildering.

For some time after the motion had died away, which motion had several maxima and minima, some little rings upon the bedstead which had been caused to swing, kept up a gentle clicking, and a night light upon a basin of oil as it swayed from side to side cast long flickering shadows across the room. The general behaviour of things was ghostly, and it was some time before I could assure myself that what I had experienced was an earthquake.

Next morning, however, my doubts were dissipated by my neighbours making jocular inquiries about the nature of my experiences. Earthquake conversation, I may remark, is often used in Yedo to fill up the gaps in conversation which in England are usually stopped by queries and truisms about the weather. This was my first earthquake.

Palmieri's instrument indicated that its direction was about E.S.E. to W.N.W., and its force was 6 degrees. By 6 degrees is meant that the shaking caused some mercury contained in a glass tube to wash up and down until a little string attached to an iron float on its surface had turned a pully and a pointer through $6^{\circ}$. By observing the tables of these indications it is seen that a very gentle shaking of long duration may get up a violent oscillation in the mercury and so indicate a sbock of a great number of degrees, whilst a violent sharp shock, which might knock over a chimney, may possibly only indicate a few degrees.

Since my first earthquake I have had the opportunity during the last six years of studying rather more than 400 other shakings. One of these shook d wn chimneys, unroofed houses, twisted gravestones, and by its action generally entitled itself to be called destructive and alarming. The effect that this earthquake produced upon the nerves of many people was quite as great as that which might be produced upon children with an imaginary ghost. As residents in Japan are so often alarmed by earthquakes it is only natural that they should be led to study these phenomena. Amongst the first instruments which were employed for their investigation were, as might be anticipated, small columns, bowls of liquid, and other contrivances, which are found described in books and papers treating of observational seismology.

Columns which have been made of various shapes and various materials have been found unsatisfactory, because it is seldom (even when a house may be swaying violently), if they are on a stone platform firmly fixed to the ground that they are overturned. When it happens that they are overturned, if there were several columns side by side you would usually find them lying pointing like the arms of a star-fish in different directions. If an earthquake was a sharp blow, no doubt the columns would fall in the direction of the shock and also towards the point from which the shock came. Yedo earthquakes, however, commence gently, and the column is caused to rock before it falls, and as it rocks its plane of rocking may be gradually changed. Another explanation would be that some of the columns had fallen with direct shocks and some with reflected shocks, or that some were overturned with the normal and some with the succeeding transverse vibrations.

Bowls of liquid have been found impracticable; first, because it is seldom that in a bowl on a firm foundation a sufficiently measurable amount of washing up is obtained; and second, that any of the usual methods of registering the motion as well as many other methods, both chemical and mechanical which have been tried, are not satisfactory. Also there are the difficulties of freezing and evaporation to contend with.

Similarly the records of the old-fashioned ordinary pendulum with a pointer resting in sand, or, what is perhaps better, provided with a sliding pointer writing over a smoked glass plate, are also very unsatisfartory. All that many of the carefully drawn records produced by swinging pendulums appear to indicate, is that there has been an earthquake, and it has caused the pendulum to swing about. For reasons like these, after considerable experience the conclusion arrived at is that the records of most of the older forms of seismographs and seismometers, of which legions have been experimented with, can only be regarded as being seismoscopic.

When we look into the history of observational seismology, and take the following description of a seismometer invented nearly 1800 years ago as a standard of comparison between the old and better known forms of earthquake instruments for registering ordinary shocks, it is doubtful whether this branch of earthquake investigation has been much advanced. This description was given to me by Mr. J. Hattori, vice-director of the Imperial University. It was translated for me by my assistant, Mr. M. Kuwabara. It runs as follows :-

In a Chinese history called "Gokanjo," we find the following: "In the first year of Yōka (A.D. 136) a Chinese called Chioko invented a seismometer. This instrument consists of a spherically formed copper vessel (Fig. I), its diameter being 8 ' shaku.' It is covered at its top. Its form resembles a wine bottle. Its outer part is ornamented with the figures of different kinds of birds and animals and old peculiar looking letters. In the inner part of this instrument a pillar is so placed that it can move in eight directions. Also in the inside of this bottle there is an arrangement by which some record of an earthquake is made according to the movement of the pillar. On the outside of the bottle there are eight dragon heads, each of which contains a ball. Underneath these heads there are eight frogs, so placed that they appear to watch the dragon's face, so that they are ready to receive the ball if it should be dropped. All the arrangements which cause the pillars when it moves to knock the ball out of the dragon's mouth are well hidden in the bottle. When an earthquake occurs and the bottle is shaken, the dragon instantly drops the ball, and the frog which receives it vibrates vigorously. Any one watching this instrument can easily observe earthquakes. With this arrangement, although one dragon may drop a ball, it is not necessary for the other seven dragons to drop their balls unless the movement bas been in all directions; thus one can easily tell the direction of an earthquake. Once upon a time a dragon dropped its ball without any earthquake, and the people therefore thought that this instrument was of no use, but after two or three days a notice came saying that an earthquake had taken place in Rōsei. Hearing of this, those who did not believe about the use of this instrument began to believe in it again. After this ingenious instrument had been invented by Chioko, the Chinese Government wisely appointed a secretary to make observations on earthquakes."

We have here I think not only an account of an earthquake instrument which in principle is identical with many of our modern inventions, but the science has been conjoined with art. The record of the Chinese Government establishing a seismological bureau at a time when America was unknown, and half of Wes:ern Europe were 
living in the woods, is also interesting. Experience having taught us that the older instruments told us so little about the actual movements which were going on at the time of an earthquake, a large number of instruments to replace them have been gradually invented. Of these I may mention the three following types.

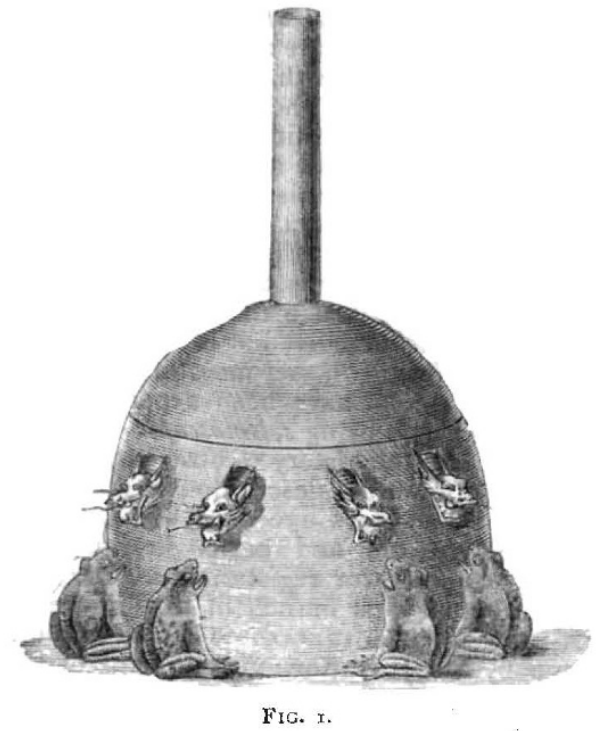

I. Pendulums, so far controlled by friction as to be "dead-beat," provided with an index which magnifies the earth's motion. The general construction of one of these instruments will be understood from Fig. 2. B B is a heavy lead ring, used as a pendulum; $\not p$ a sliding pointer loaded with lead (so that it may give sufficient

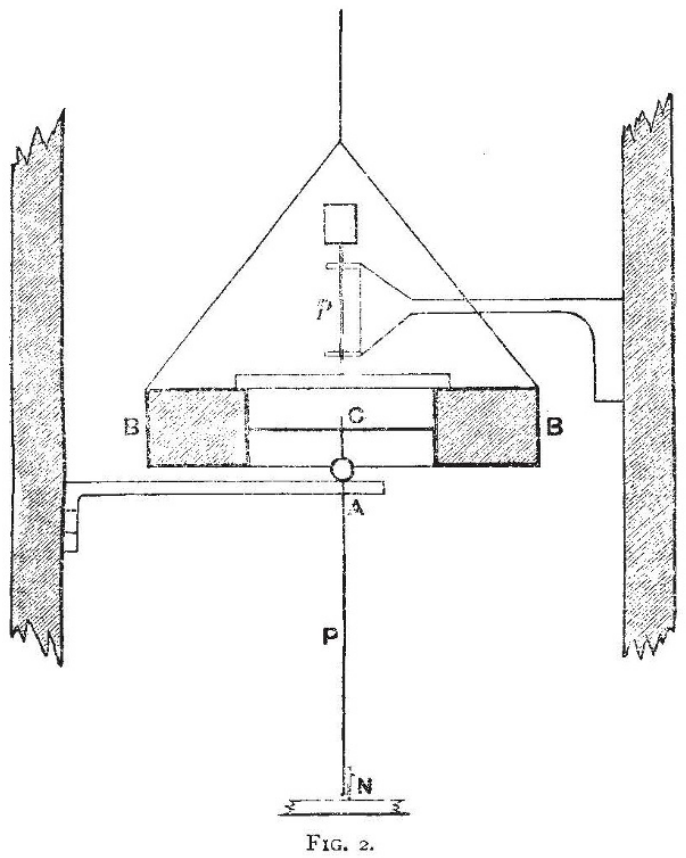

friction), resting on a glass plate on the pendulum. This pointer is carried by an arm attached to the side of the box containing the pendulum. Its object is to control the swinging of the pendulum. $\mathrm{P}$ the index, axled near the centre of gravity, $\mathrm{C}$, of the pendulum, and again a short distance below at $\mathrm{A}$ in an arm attached to the side of the containing box. At the lower end of this index there is a sliding needle, $\mathrm{N}$, to write on a moving or stationary glass plate. The magnification of the actual motion of the earth in this instrument is as C A : A N.

2. Bracket Machines (see Fig. 3). B is a heavy weight pivoted at the end of a small bracket, $\mathrm{CA} \mathrm{K}$, which bracket is free to turn on a knife edge $\mathrm{K}$ above, and a pivot $\mathrm{A}$ below, in the stand $\mathrm{S}$. At the time of an earthquake $B$ remains steady, and the index $P$ forming a continuation of the bracket, magnifies the motion of the stand, which is to that of the earth in the ratio of $\mathrm{A} \mathrm{C}: \mathrm{CN}$. These instruments are used in pairs, the brackets in each being placed at right angles to each other.

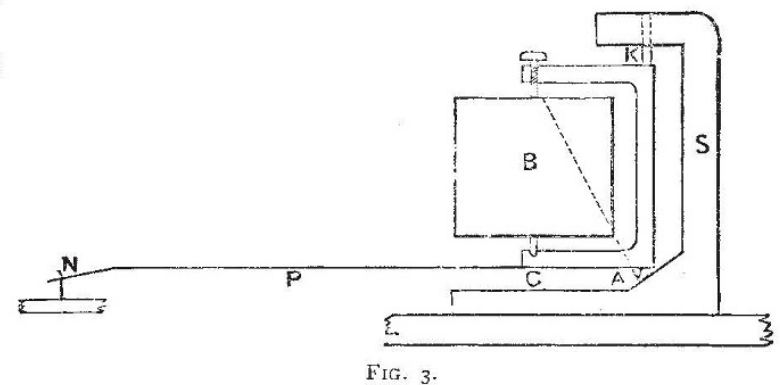

3. Rolling Spheres (Fig. 4). $\mathrm{S}$ is a segment of a large sphere with a centre near C. Slightly below this centre a heavy weight, $\mathrm{B}$, which may be a lead ring, is pivoted. At the time of an earthquake $C$ is steady, and the earth's motions are magnified by the pointer $\mathrm{CA} N$ in the proportion of CA : A N. The working of this pointer or index is similar to that of the pointer in the pendulum.

The indices of all these instruments, of which there are many modifications, are allowed to write on smoked glass plates, which at the time of an earthquake are either being moved by clockwork or else are stationary. For vertical motion, sunken buoys, the water in a can with a flexible bottom, and a weight suspended at the end of the long

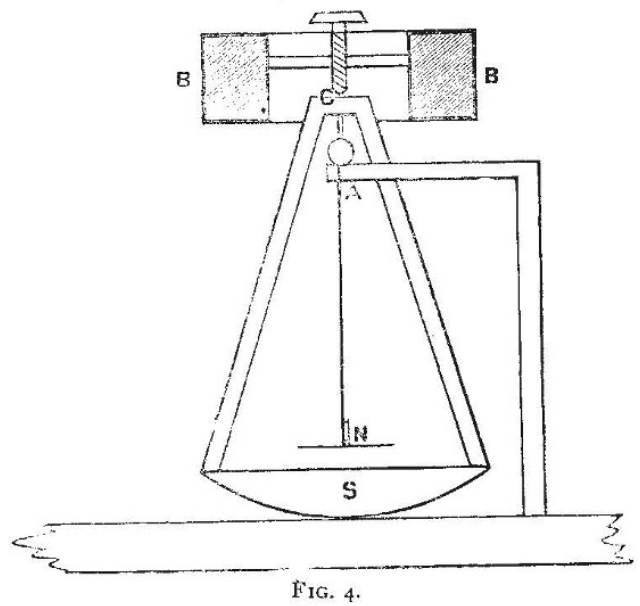

arm of a lever and stretching a stiff spring, have all been used with more or less success as steady points in the recording of vertical motion.

For the invention of the greater number of these instruments, which I may remark have already done very much in writing down actual earthquake motion, we are indebted to Mr. T. Gray. Messrs. Ewing, Chaplin, Wagner, and other members of the Seismological Society of Japan, have also made valuable contributions to this part of the subject.

Some of the more important results which have been arrived at by the use of these and other instruments are .- 
I. That the earthquakes in Tokio usually commence gently, the motion is irregular, both as regards space and time, increasing and decreasing. Finally it dies away as it commenced.

2. There are usually from two to three vibrations per second. Occasionally there may be six or eight.

3. The maximum amplitude of an earth particle is seldom over one millimetre, although buildings may swing through several inches. When the amplitude is four or five milliruetres, and the motion rapid, the shock may be dangerous.

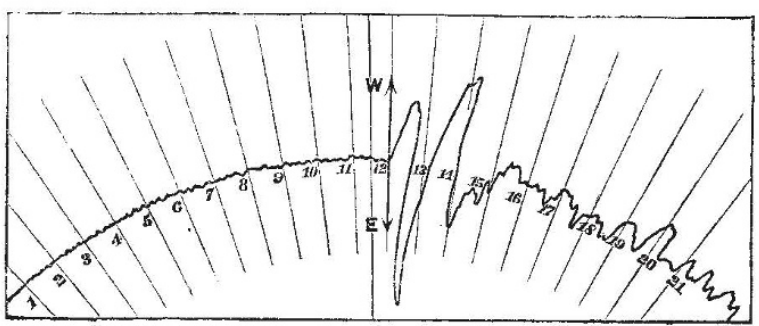

EiG. 5 .

4. During a given shock the direction of motion may change, apparently showing the presence of normal and transverse vibrations.

5. The motion of the ground inwards towards the origin of the disturbance has in certain cases been much greater than the motion outwards. In this respect the diagram obtained from an actual earthquake closely resembles the diagram obtained when we explode a charge of dynamite in a bore hole.

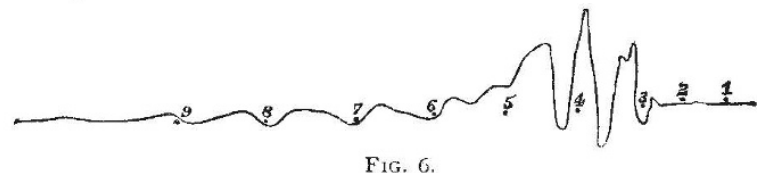

6. The velocity, and with it the acceleration for the inward motion, is usually much greater than it is for the outward motion.

In addition to these characters, earthquake motion has others which are more complex, and are now forming a subject of examination. Thus, for instance, experiment apparently indicates that two neighbouring points of ground (say at the distance of two feet from each other) do not synchronise in their motion. This would indicate that a builfing, although it may be small, may not be

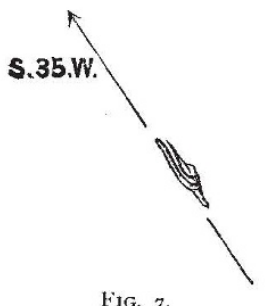

moved back and forth as a whole, but may suffer considerable racking.

The intervals in time between the actual earthquakes, which on the average occur from six to ten times per month, have been filled up with experiments upon artificially produced earthquakes, made by exploding charges of dynamite and gunpowder in bore holes. These experiments, in which the vibrations of the ground produced by the explosions have been simultaneously written down at a number of different stations, have perhaps been more instructive than the actual earthquakes. They have been to seismology what laboratory experiments on magnetism have been to the student of the magnetic phenomena of the earth. Not only bave results similar to those which have been enumerated for actual earthquakes been obtained, but also many others. Thus it is found that in the alluvium of the Tokio plain a surface wave is produced, as might be inferred from the fact that the observation of the horizontal and vertical components of the motion of the ground, do not enable us to deduce angles of emergence for the shock and the depth of its origin. Normal and transversal vibrations have been clearly separated. The effect produced by inequalities in the surface of the ground in cutting off the propagation of vibrations have been studied. Small hills appear to produce but a slight

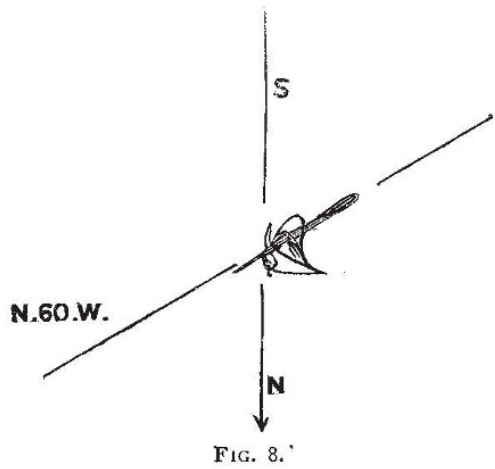

effect, whilst cuttings (like a deep pond) are more or less effective in interrupting a disturbance.

By the comparison of a number of diagrams of earth vibrations, taken simultaneously at different stations, it has been an easy matter to investigate the relative amplitudes of different vibrations. Near to the origin of a dis. turbance the amplitude of the normal vibrations was found to be greater than that of the transversal ones, but the former, as they progressed outwards, died out more quickly than the latter. The diminution in the period of these vibrations as they died out at a single station, or as they died out by propagation to distant stations, was alsc a matter of considerable importance. In connection with this subject it does not seem impossible that when we have a large earthquake, say like that of Lisbon in 1755,

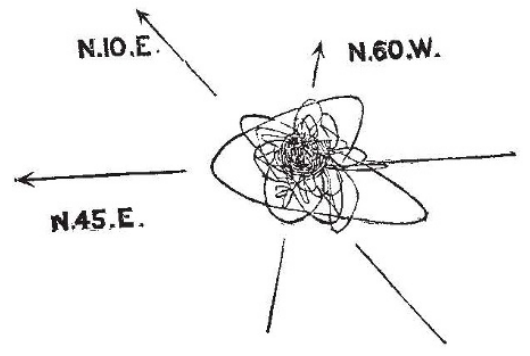

Fig. 9.

that the vibrational period of the disturbance may gradually be so far reduced, although its amplitude may be great, that inhabitants in distant countries may be moved backwards so slowly that the only indication of the motion would be a slow rising and falling in the waters of their lakes and ponds.

May not certain disturbances of this nature, like the seiches of Switzerland, usually attributed to variations in atmospheric pressure, be sometimes caused by slow oscillations of this description?

Sir William Thomson has suggested that Mr. George Darwin should employ the same reasoning to discuss these phenomena as that which he has so well employed to discuss the elastic yielding of the earth in connection with 
the rise and fall of tides. Sudden alterations in barometrical pressure may possibly produce earthquakes of large amplitude and slow period, similar to those here referred to, which hitherto have been passed by unnoticed. The following are examples of the various records which have been referred to.

The diagram (Fig. 5) is a tracing from a photograph of the east and west component of the earthquake of March II, 1882, as recorded in Tokio. The regularly marked intervals represent seconds of time. For about 12 seconds before the shock there was a rapid tremulous motion. It will be observed that the westward motion of the shock is less in amplitude, and has been performed more slowly than the eastward motion. The origin of the shock was to the S.S.E. After the shock, which had a maximum amplitude of about $3.5 \mathrm{~mm}$., the motion died out irregularly. Altogether the earthquake lasted about $\mathrm{I} \frac{1}{2}$ minutes. Prof. Ewing, who recorded this same disturbance at a station about a mile distant, recorded a maximum motion of $6 \mathrm{~mm}$., and the duration of the disturbance could be traced over a period of about $4 \frac{1}{2}$ minutes.

Fig. 6 represents the normal motion of the ground produced by exploding about 2 lbs. of dynamite in a bore hole about 8 feet deep. The distance at which the seismograph was placed from the explosion was 100 feet. The intervals represent half seconds of time. The upward movement indicates motion inwards towards the origin of the disturbance.

The three diagrams (Figs. 7, 8, 9) are diagrams of actual earthquake motion, as drawn by a pendulum seismograph on stationary smoked glass plates.

Fig. 7 an earthquake at Chiba ( 16 miles E. of Tokio), 11.49.0 p.m., February 16, I882. Here the motion has been simply in one direction, S. $35^{\circ} \mathrm{W}$. Its extent is about $9 \mathrm{~mm}$.

Fig. 8 an earthquake at Chiba, December 23, I88I. Here the motion has been in at least two directions, N. and S., and N. $60^{\circ} \mathrm{W}$. The maximum amplitude is about I $\mathrm{mm}$.

Fig. 9 an earthquake at Tokio, 4.15 .0 p.m., March 8, 1882. Here there has been motion in several directions. The maximum amplitude is about $2 \cdot 2 \mathrm{~mm}$.

Another class of seismic experiments which, although they are by no means sufficiently complete have yielded good results, are those in which time observations have formed the important features. One result of these experiments, in addition to telling us the side and locality from which earthquakes have come, has been to show that the direction in which the ground has vibrated has sometimes been at right angles to the direction in which the disturbance was being propagated. The chief results, however, have been with regard to the velocity of propagation. These may be epitomised as follows:-

I. Different earthquakes, although they have travelled across the same district, have done so with different velocities.

2. The greater the initial disturbance the greater the velocity of propagation.

3. The same disturbance is propagated with a decreasing velocity.

These results it may be remarked have received direct confirmation, both for normal and transverse motions, in experiments made by exploding charges of dynamite.

Another point which has received considerable attention has been the production of what are apparently earth currents at the time of an artificial disturbance.

A problem of local interest which has been worked at for some years has been the localisation of the origins of the shocks which from time to time disturb the eastern shores of Japan. The result of these labours has shown that the greater number of shocks have originated beneath the sea, off a coast which shows clear evidence of recent and rapid elevation.

A phenomenon which has clearly been illustrated in these investigations has been the very rapid manner in which heavy mountain ranges have completely prevented the spread of a disturbance.

By placing a large number of similar seismographs on the hills and in the valleys of a limited area, it has been quantitatively demonstrated that we may have two localities within a quarter of a mile of each other, one of which will experience at least double the amount of disturbance as the other. In some localities the hills appears to be the most affected, at others the plains are the troubled regions.

Having before us the diagram of an earthquake, and knowing its origin relatively to the locality where it was drawn, by comparing this with the diagram produced by the explosion, say, of 5 lbs. of dynamite at the distance of 100 feet, we are now enabled to calculate in pounds of dynamite or other units a value for the impulse which created the earthquake.

Not only have earthquakes been investigated, but with the help of microphones and apparatus similar to that employed by the Brothers Darwin at Cambridge, a good deal of attention has been given to the recording of earthtremors. The results of these investigations have not as yet been sufficient to enable us to form any general laws such as those which have been formulated by Prof. Rossi and other workers in the Italian Peninsula.

A utilitarian branch of seismology has been a study of the effects which have been produced upon buildings. Walls with openings in them, which run parallel to the direction in which there is the greatest motion, appear to be more cracked than those at right angles to such directions. At the time of an eartbquake existing cracks in a building have been found to open and shut. Records of these motions have been obtained by means of specially contrived indicators placed across the cracks. Other cracks which had been marked and dated at their extremities appear to have extended. The effects of placing brick chimneys with wooden houses, giving too steep a pitch to a roof, causing archways over doors and windows to meet their abutments at sharp angles, have been objects of observation. The difference in the effects produced upon buildings like those of the Japanese, which simply rest upon the surface of the ground, and those which by means of foundations are firmly attached to the soil, have yielded instructive lessons. In short it would seem that for earthquake countries the rules and formulæ used by engineers and architects require considerable modification. In England the principal elements which enter into consideration, are stresses and strains produced by gravity acting vertically. In an earthquake country we have in addition sudden stresses and strains arising from forces applied more or less horizontally.

After the lessons placed before us by the ruins which earthquakes have produced in various portions of the globe, should we undertake any great engineering work in an earthquake country, as, for instance, the Panama Canal, without first having carefully considered how best to avoid the evils arising from the sudden acquisition of momentum consequent on seismic disturbances, is for shareholders in these undertakings a financial suicide. Because earthquakes are strong the usual method to meet them is by strong construction. Still very much more than this may be done. And if we cannot prevent the destructive effects of earthquakes, observation in Japan has shown that we can at least mitigate them. This is testified by the modification in the style of buildings now adopted in Japan by all who suffered by the earthquake of February 22, 1880.

The observation of earthquakes in Japan has therefore led to results which are utilitarian as well as scientific. The description which has here been given of the work which is going on in that country is short and imperfect, many branches of seismological investigation which have been taken up has not even been referred to. 
In conclusion I must draw attention to the excellent opportunities which many of those residing in Britain have for the observation of artificially produced earth tremors. By these I mean the vibrations which are produced by our railway trains, our carriages, explosions at mines and quarries, steam hammers, the falling of balls used in the breaking of castings, and other means. All of these vibrations I can state with confidence are capable of being graphically recorded, and the value of a series of such records to the practical seismologist it is hardly necessary to dilate upon.

Investigations of this description are the laboratory work of the practical seismologist, and often lead to more valuable results than those which are obtained from actual earthquakes. Actual earthquakes are produced by unknown causes, they come at unknown times, and from unknown localities. With artificially produced disturbances none of these difficulties have to be contended with, the cause and the result are before us simultaneously, and we are enabled to arrive at laws which actual earthquakes would never yield to us.

Another point to which I should like to draw attention is the study of earth movements in general. Hitherto we have only devoted our attention to the sudden and violent movements which we call earthquakes. In addition to these we have in nature movements of less amplitude called earth tremors. Inasmuch as we now know that these are probably a universal phenomenon, and at the same time are in every probability governed by laws simpler than those which govern earthquakes which are usually due to a complexity of causes, it certainly devolves upon us to establish the necessary means for their investigation. From the little we have learnt about earth tremors it is not unlikely that they may be to our continents what tides are to our oceans, phenomena which are regular and law abiding, and not like the earthquakes, which may be compared to the storms of the ocean.

In addition to these motions of small amplitude we have many reasons for believing in the existence of motions of our ground of great amplitude, but so slow in period that hitherto they have been overlooked.

In order to complete the study of earth motions we have to add to seismology the study of earth tremors and what might be called earth pulsations.

As we have done so much for our skies, for our atmosphere, and for our waters, we can surely do a little towards the investigation of the movements of the earth on which we live.

Although these latter remarks have no direct connection with the work which has been accomplished in Japan, they are nevertheless an outcome of such work, and if they tend in any way to draw attention to a much neglected study, an object will have been attained greater than any which could be hoped for by diffusing a knowledge of the labours of those who dwell at our Antipodes. JOHN MILNE

\section{THE LATE PROFESSOR BALFOUR}

THE meeting held last Saturday to establish a memorial to the late Prof. Balfour was very largely attended by all grades in the University, and among nonresidents by Professors Huxley, H. J. S. Smith, A. W. Williamson, W. K. Parker, Ray Lankester, H. N. Moseley, and A. M. Marshall and Mr. George Griffith, of Harrow. The president of the Royal Society would have boen present but for bis recent accident. The speakers, including most of those mentioned above, and Professors Paget, Humphry, Newton, and Westcott, bore unanimous testimony to the high regard and affection in which the lamented professor was held, to the original work he had accomplished, and the high promise of his life, and to the energy and success of his teaching. Dr. Paget referred to Balfour's having abandoned his favourite pastime of deer-stalking in order not to inflict unnecessary suffering upon harmless animals, and his having taken up instead that of Alpine climbing, in which he met his death. Any memorial to him would, he hoped, do something to perpetuate the spirit in which his scientific achievements had been accomplished, which placed him beside such men as Miller, Sedgwick, and Clerk Maxwell. Mr. A. Sedgwick, late demonstrator with Balfour, spoke of the growth of the class in seven years from ten to ninety students, and of the crushing nature of his loss to the school he had attracted around him, for his personal intercourse and counsel was of the extremest value.

Prof. Huxley, in proposing "That the memorial take the form of a fund, to be called the Balfour Fund, for the promotion of research in biology, especially animal morphology," said that after the addresses they had listened to with painful interest, it would be superfluous for him to add his personal testimony to the remarkable sagacity and the remarkable characteristics of Prof. Balfour. It was no exaggeration to say that in his eyes and to many of his age he seemed to be like Lycidas, of whom Milton wrote, "who died in his prime and hath not left his peer." The remarkable capacity he exhibited was developed by a multitude of surrounding circumstances. $\mathrm{He}$ was happy to say that he personally had contributed, amid a multitude of more powerful forces, to that which led to the development of his great powers. When Balfour was a young man, a paper he had written while at Harrow School was sent to him for his judgment, and again when Balfour was a candidate for a Fell'swship at Trinity College, he was one of the examiners. "Amid many of my faults and failings during a long life," said Prof. Huxley, "I do not reproach myself for neglecting to recognise the capacity of the friend we have lost, both in the paper written while at Harrow and during the examination for the Fellowship at Trinity." $\mathrm{He}$ would draw attention to two words in the resolution he proposed-viz., research and morphology. The late Professor distinguished himself in both these directions. In former days men were content with being learned, but now we must not only know what is known, but help to extend the bounds of knowledge. This Balfour did. and his title as an eminent researcher was undoubted. With regard to morphology, it was a science until recently only known as a field of wide speculation of German philosophers. It was now a new learning, a great system of doctrine, established by an enormous mass of carefully co-ordinated facts. Three things were requisite to develop this new science:-I. Mastery of practical methods. 2. Accuracy of observation. 3. Vividness of imagination. He had never met any one more marvellously gifted with these three great qualities than Prof. Balfour. If his unshrinking modesty could have foretold this meeting, there would not be any form of memorial more entirely grateful to his feelings than the one proposed. A monument in stone or brass would be inappropriate; but to establish through this fund a perennial spring of activity in the direction of the study he pursued would be a more lasting and perfect memorial. And they might think of him in the consluding words of "Lycidas":- "Henceforth thou art the genius of the shore, In thy large recom pense, and shalt be good To all that wander in that perilous flood"

Prof. Newton proposed "That the proceeds of the fund be applied (I) to establish a studentship, the holder of which shall devote himself to original research in biology, especially animal morphology ; (2) to further, by occasional grants of money, original research in the same subject." He said that the room and the building in which they were assembled reminded him that he felt and entered for the first time into the full meaning of the Poet Laureate's words- "But O! for the touch of a vanish'd hand And the sound of a voice that is still." With refer- 